\title{
Intelligence and the Gene for Duchenne Muscular Dystrophy
}

\author{
E. JANE PROSSER, E. G. MURPHY, and MARGARET W. THOMPSON \\ From the Neurological Service and Department of Genetics, The Hospital for Sick Children, \\ and the Faculty of Medicine, University of Toronto, Canada
}

Duchenne muscular dystrophy (DMD) is a primary myopathy determined by an $\mathrm{X}$-linked gene. In addition to causing muscle wasting and physical disability, DMD is associated with a concomitant reduction in intellectual functioning. This paper reports data obtained by psychometric evaluation of a series of patients with DMD, their sibs, and of heterozygous female relatives of these patients (carriers).

Though the earliest clinical descriptions of DMD noted accompanying mental subnormality (Duchenne, 1868; Gowers, 1879; Erb, 1891; Bramwell and Addis, 1913), not all workers agree that intellectual impairment is present. Some researchers have found the incidence of mental retardation among dystrophics to be the same as that among the general population (Bell, 1943; Walton and Nattrass, 1954; Schoelly and Fraser, 1955; Sherwin and McCully, 1961; Gamstorp and Smith, 1964), while others explain the slightly lower intelligence scores found in their studies on the basis of environmental consequences of chronic disease, and/or socio-economic status (Morrow and Cohen, 1954; Truitt, 1955). There is now, however, a substantial body of evidence showing decreased mental functioning in DMD patients (Zellweger, 1946; Becker, 1953; Giannini and Marcheschi, 1959; Walton, 1963). The reports since 1960 to this effect are summarized in Table I.

In addition to the studies listed, Suga et al. (1966) reported severe mental retardation in 7 members of a kindred who were also afflicted with what appeared to be $\mathrm{DMD}$, though it was interchangeably referred to as 'atrophy'. Rosman and Kakulas (1966) presented a neuropathological study of 12 cases of muscular dystrophy based on necropsy reports; 6 of their subjects (including 3 cases of DMD) had well-documented evidence of mental defect.

Received August 30, 1968.
In the present study, the following questions were asked:

(1) To what extent is the intelligence of boys with DMD impaired? (2) Is the impairment progressive? (3) Is the impairment uniform, or more marked in certain areas than in others? (4) Is severe muscular disability the cause of the impairment? (5) Is a lower intelligence quotient (IQ) found because the patient derives from a low socio-economic stratum? (6) Does the intellectual impairment in patients reflect varying genetic backgrounds? (7) Does the Duchenne gene affect the intelligence of heterozygous females ? and (8) Is the intelligence of children of heterozygous females lower than that of children of normal females?

The expression of the DMD gene in heterozygous female carriers is of interest in view of the Lyon hypothesis of the action of X-linked genes in female mammals (Lyon, 1961, 1962). Examples include numerous reports of increased levels of activity of certain serum enzymes in the blood of carrier women (e.g., Emery, 1965; Smith, Amick, and Johnson, 1966; Thompson, Murphy, and McAlpine, 1967), reports of muscle weakness in a minority of heterozygotes (Emery, 1963; Emery and Lee, 1964; Murphy et al., 1964; Thompson and Murphy, 1964; Murphy and Thompson, 1969, in the press), descriptions of abnormalities of muscle in biopsies (Emery, 1963, 1964, 1965), and a report of cardiac involvement (Murphy et al., 1964). It is of interest, therefore, to test the intelligence of carriers to determine if they also have a reduction in mental functioning.

The carrier women who have reported muscle weakness have usually had very high levels of serum creatine kinase (CK) activity, and muscle biopsies showing a fairly high percentage of myopathic fibres (Emery, 1963; Emery and Lee, 1964; Murphy et al., 1964; Murphy and Thompson, 1969 , in the press). If intellectual depression is an 
TABLE I

Intelligence Quotients of Duchenne Dystrophy Patients

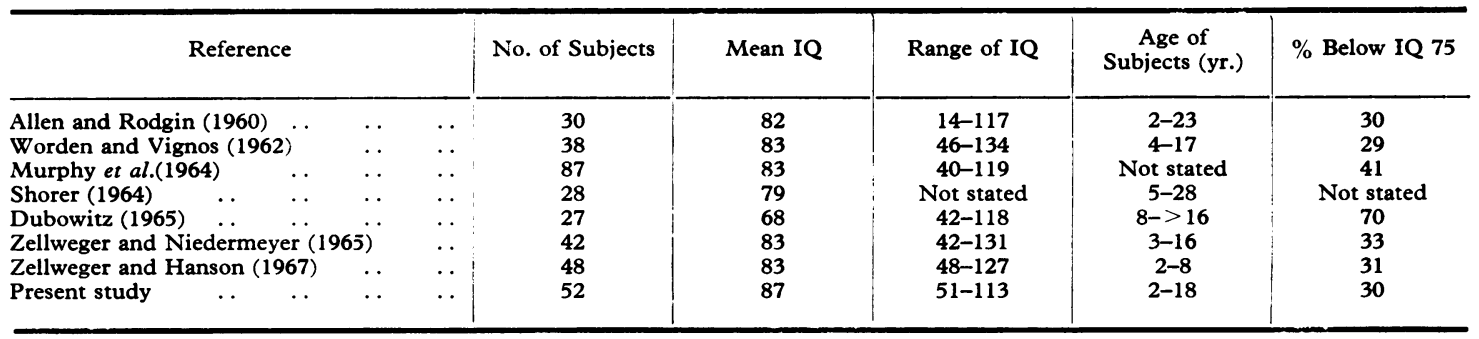

aspect of the phenotype of carrier women, it might be most obvious in these so-called 'manifesting heterozygotes'.

\section{Material and Methods}

Subjects. The definition of DMD used in the present study has been restricted to a genetically and clinically uniform group of cases, phenotypically resembling the severe $\mathrm{X}$-linked type, the characteristics of which are described by Walton (1963).

Though all forms of X-linked muscular dystrophy are single-gene disorders, it does not follow that these represent identical mutations, nor is there any reason to believe that X-linked muscular dystrophy is necessarily produced by mutations at a single locus. One can only infer in humans that traits with similar phenotypes and the same pattern of inheritance are caused by the same mutation.

The relatives of the propositi were classified as heterozygous or normal on the basis of biochemical and genetic criteria. Three criteria were used to classify female family members as carriers.

A. Biochemical. Women with serum $\mathrm{CK}$ activity above the upper limit of normal, which in our laboratory is 1.8 units $\left(\mu \mathrm{m}\right.$. creatine $/ \mathrm{ml}$. serum per hour at $37^{\circ} \mathrm{C}$.). False positive findings rarely occur, so that an increase in $\mathrm{CK}$ activity in a clinically normal female relative of a DMD patient is a reliable sign of heterozygosity (Thompson et al., 1967).

$B$. Genetic. (1) A woman with at least one affected son or carrier daughter and another affected relative, usually a brother but occasionally a more distant relative in a pattern of kinship concordant with X-linked recessive inheritance. (2) A woman with two or more affected sons, or at least one affected son and one or more carrier daughters, but no known affected relative.

The normal control group consisted of family members who were unaffected males, or females with $\mathrm{CK}$ values of 1.8 units or less.

A DMD patient was the propositus of each family used. Since three groups of subjects (patients, carriers, normals) were required, families with carrier daughters were selected as often as possible, and in no instance was a family with only one child included.
Materials. Three standard intelligence tests were used: the Wechsler Intelligence Scale for Children (WISC), the Wechsler Adult Intelligence Scale (WAIS), and the Stanford Binet, form L (SB). The means and standard deviations of the three tests are fairly close numerically, making possible the comparison of IQ's at the numerical level (Wechsler, 1949). Wechsler tests were favoured as they produced individual subtest scores, each with a mean of 10 points, as well as three separate intelligence quotients; verbal $I Q$, performance IQ, and total IQ, with a mean in each case of 100 points. Since one aim of the study was to detect specific areas of intellectual deficiency in the DMD patients, the subtest scores were useful. As DMD patients become progressively disabled, one might expect their performance, involving hand and arm movement, to be hindered. Separate scores for verbal and performance aspects of the IQ are consequently of special interest in such a group.

\section{Results}

IQ scores of normal group. 57 normal family members had a mean IQ of $106 \cdot 1$ with a standard deviation of $15 \cdot 2$, and a range of 57 to 137 .

IQ scores of muscular dystrophy patients.

(1) Comparison of IQ's of DMD patients and unaffected sibs. To compare the scores of DMD patients and their normal sibs, the mean IQ of the patients was paired with the mean IQ of their sibs in each sibship. An $R \times 2$ analysis of variance (Snedecor, 1956) was performed on the paired data obtained in 34 sibships. The range and distribution of the 2 groups are shown in Fig. 1, together with normal curves fitted to both groups of data. Table II shows the mean IQ's of the dystrophics and unaffected sibs, and the $F$ ratios obtained by analysis of variance.

The $F_{1}$ ratio indicates that the mean IQ is significantly lower in the dystrophics than in the unaffected sibs. A significant $F_{2}$ ratio merely reflects the well-known fact that sibships differ in IQ. The significant $F_{3}$ ratio shows that the 


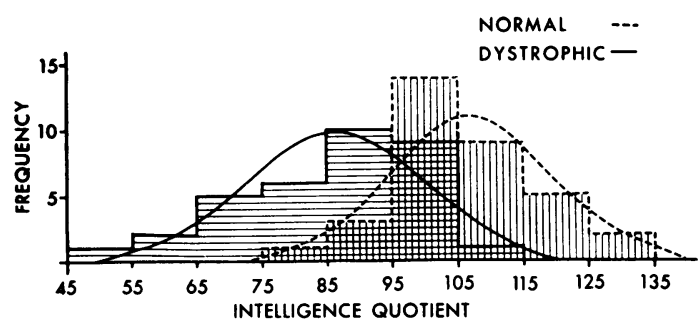

FIG. 1.-Comparison of IQ's (sib mean) of dystrophics and unaffected sibs in 34 sibships.

magnitude of the difference between dystrophics and unaffected sibs is not consistent from sibship to sibship.

(2) Comparison of IQ's of DMD patients and normal brothers. Since the present study has not shown a difference in IQ between carriers and normals (see later; Fig. 6), the inclusion of both types in the 'unaffected sibs' category of the previous analysis of variance should not affect the $F$ ratios obtained. However, to eliminate sex differences and any question of genetic misclassification of genotype, a second analysis of variance was performed on the data obtained in 22 sibships by pairing the mean IQ in DMD patients and their normal brothers. The range, distribution, and normal curves fitted to these data are shown in Fig. 2. The mean IQ's of the dystrophics and their normal brothers, and the $F$ ratios obtained by analysis of variance are shown in Table III. The $F_{1}$ ratio is highly significant, indicating that the mean IQ of the dystrophics is significantly different from that of their normal brothers. (Significant $F_{2}$ and $F_{3}$ ratios have previously been explained.)

An interesting observation to be made from both these analyses of variance is that the $F_{3}$ ratio,

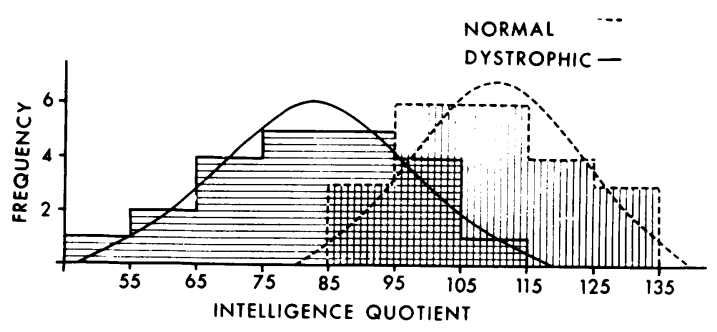

FIG. 2.-Comparison of IQ's (sib mean) of dystrophics and normal brothers in 22 sibships.

or $F$ ratio for interaction, is significant at $<0.01$. This indicates that the magnitude of the difference between the two groups differs significantly from sibship to sibship, that is, that while in general the IQ of the dystrophics is lower than average, the amount of the IQ reduction varies from family to family. A similar inference can be made from the significant positive correlation found between the IQ's of normal sibs and the difference in IQ between normal sibs and dystrophics (see later; Fig. 7), indicating that there is a greater disparity between the mean scores in bright families than in dull families.

\section{Impairment in DMD patients.}

(1) Incidence. The distribution of IQ scores in dystrophic children as compared to the normal range (Wechsler, 1949) is shown in Table IV. It will be noticed that $31 \%$ of the dystrophic patients fall into the borderline and mental defective categories as compared to $9 \%$ of a normal population. Zellweger and Niedermeyer (1965) selected an IQ of 75 rather than 79 as the boundary below which mental retardation is found. Table I shows their results as well as figures similarly derived from

TABLE II

Mean IQ's and Analysis of Variance of the IQ's of Dystrophics and Unaffected Sibs

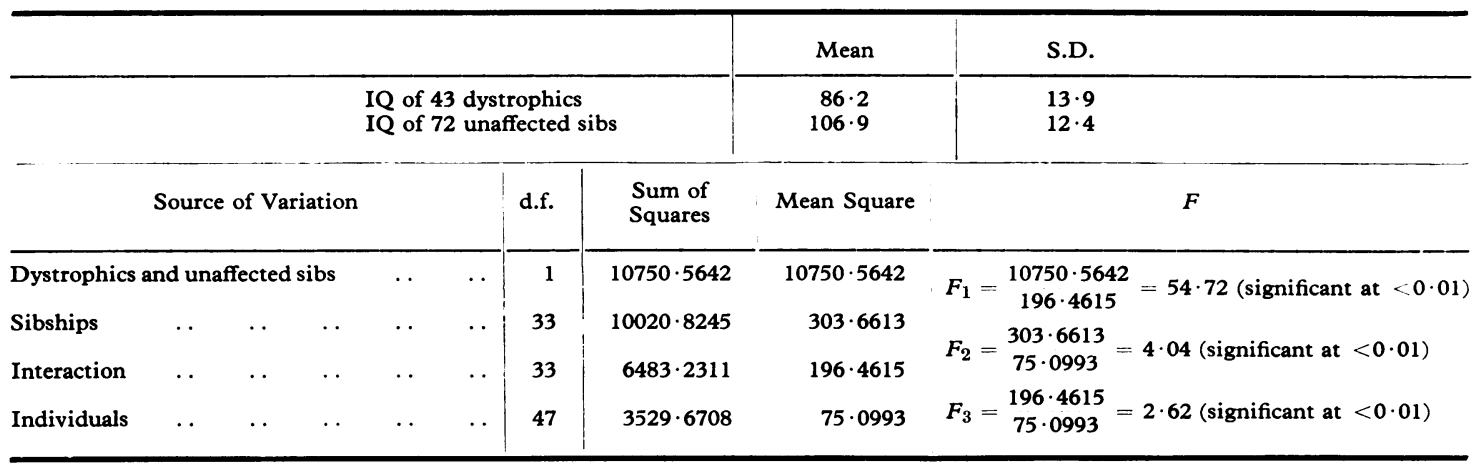


TABLE III

Mean IQ's and Analysis of Variance of IQ's of Dystrophics and Normal Brothers

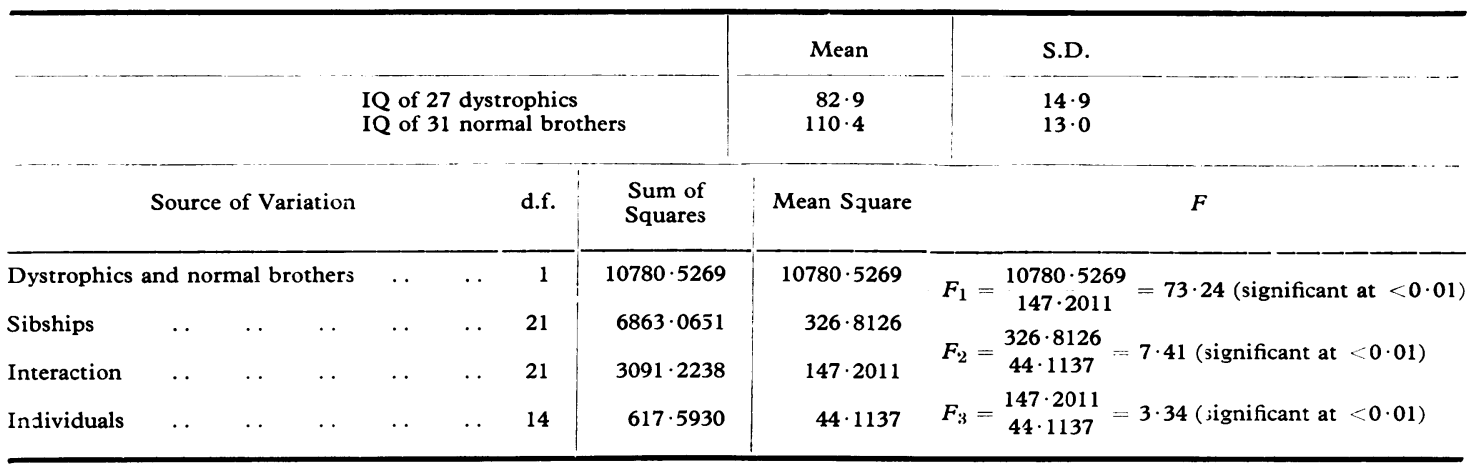

several other studies. It is clear that about $30 \%$ of muscular dystrophy patients are mentally handicapped, and that their mean IQ falls approximately $1 S D$ (in IQ points) below the population mean.

(2) Extent. The mean, standard deviation, and range of the IQ scores for 47 DMD patients are shown in Table V. The majority of investigators has found a mean IQ of 83. Probably because the patients psychometrically assessed by Dubowitz (1965) were long-term in-patients, the mean IQ of 68 found by him is lower than those reported by others. The mean IQ of $87 \cdot 2$ found in the present study is slightly higher than the values previously reported. While the data available do not permit determining if the difference is significant, the discrepancy may have been caused by a consistent error in testing, or by the omission from statistical analysis of 4 patients with IQ's of less than 50 to whom numerical scores were not assigned.

Nature of defect: static or progressive.

(1) Serial testing. 29 cases of DMD were retested after a 2- to 6-year interval. The observa-

TABLE IV

Distribution of IQ Scores in Dystrophic and Normal Children

\begin{tabular}{c|llc}
\hline IQ & \multicolumn{1}{|c}{ Category } & $\begin{array}{c}\text { Dystrophic } \\
(\%)\end{array}$ & Normal (\%) \\
\cline { 1 - 3 } 130 and above & Very superior & 0 & 2 \\
$120-129$ & Superior & 0 & 7 \\
$110-119$ & Bright normal & 6 & 16 \\
$90-109$ & Average & 35 & 50 \\
$80-89$ & Dull normal & 29 & 16 \\
$70-79$ & Boderline & 10 & 7 \\
69 and below & Mental defective & 21 & 2 \\
\hline
\end{tabular}

* Based on data for 52 dystrophics. tions were as follows: previous mean IQ, 88.1 (SD 14.2); present mean IQ, 87.5 (SD 13.7) $(t=0 \cdot 336$, not significant $)$.

Our results are in agreement with those of Zellweger and Hanson (1967), who showed that 19 patients evaluated through multiple tests during different stages of their disease scored consistently at approximately the same level. Jones (1965) suggests that a slight practice effect is found in serial testing. This was minimized in the present study as initially most tests were SB, while the second series consisted chiefly of Wechslers. Individual changes in IQ ranged from an increase of 20 points to a decrease of the same number. Scheinfeld (1950) appears to be the only investigator who has proposed that the mental retardation is progressive, but his opinion is supported neither by reference nor by evidence.

(2) Correlation between age and IQ. A second approach to the problem of the progressive nature of the mental retardation in DMD patients was the calculation of correlation coefficients between age and the three IQ scores obtained (total, verbal, and performance). The results are summarized

\section{TABLE V}

Intelligence, Age, and Family Income of 47 Dystrophics

\begin{tabular}{lcc|c|c|c}
\hline & & Mean & SD & Range \\
\hline Total IQ & $\ldots$ & $\ldots$ & $87 \cdot 2$ & $14 \cdot 1$ & $51-113$ \\
Verbal IQ & $\ldots$ & $\ldots$ & $87 \cdot 1$ & $16 \cdot 5$ & $50-115$ \\
Performance IQ & $\ldots$ & $88 \cdot 0$ & $14 \cdot 2$ & $61-122$ \\
Age (yr./mth.) $\ldots$ & $\ldots$ & $9 / 7$ & - & $2 / 4-18 / 7$ \\
Income (per annum) & $\ldots$ & $\$ 6533 \cdot 53$ & - & $\$ 3120-\$ 12,000$ \\
& & & & \\
\hline
\end{tabular}

\footnotetext{
^ Based on data for 39 dystrophics.
} 
TABLE VI

Correlation Between Age and IQ in Muscular Dystrophy Patients

\begin{tabular}{|c|c|c|c|}
\hline & $\begin{array}{l}\text { No. of } \\
\text { Patients }\end{array}$ & Correlation & Significance \\
\hline $\begin{array}{ll}\text { Total IQ } & \ldots \\
\text { Verbal IQ } & \ldots \\
\text { Performance } & \text { IQ }\end{array}$ & $\begin{array}{l}47 \\
39 \\
39\end{array}$ & $\begin{array}{l}+0 \cdot 141 \\
+0 \cdot 384 \\
+0 \cdot 102\end{array}$ & $\begin{array}{l}\text { Not significant } \\
\text { Significant at }<0.05 \\
\text { Not significant }\end{array}$ \\
\hline
\end{tabular}

in Table VI. Since dystrophics become progressively incapacitated with increasing age, a negative correlation would support the progressive nature of mental retardation. However, no significant correlation was found between age and total IQ, or age and performance IQ (Fig. 3 and 4). Surprisingly, a significant positive correlation was found between age and verbal IQ (Fig. 5). Sherwin and McCully (1961) found little evidence that children, including the brightest ones, tended to compensate for motor deficiency by concentration on verbal activities and interest, but such compensation is suggested by the significant increase in verbal IQ with increasing age shown in this study.

\section{Uniformity of intellectual impairment.}

(1) Verbal and performance IQ's. The verbal and performance IQ's were compared in 39 dystrophics, and a t-test was done on the differences between them as follows: mean verbal IQ, 87.1 (SD 16.5); mean performance IQ, 88.0 (SD 14.2) $(\mathrm{t}=0.065$, not significant).

Several papers have reported the mean per-

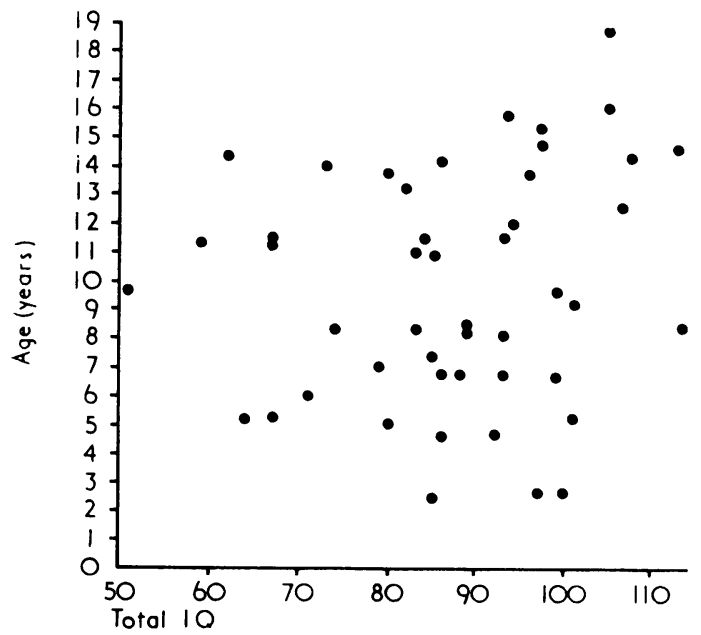

FIG. 3.-Correlation between age and total $I Q$ in 47 dystrophics.

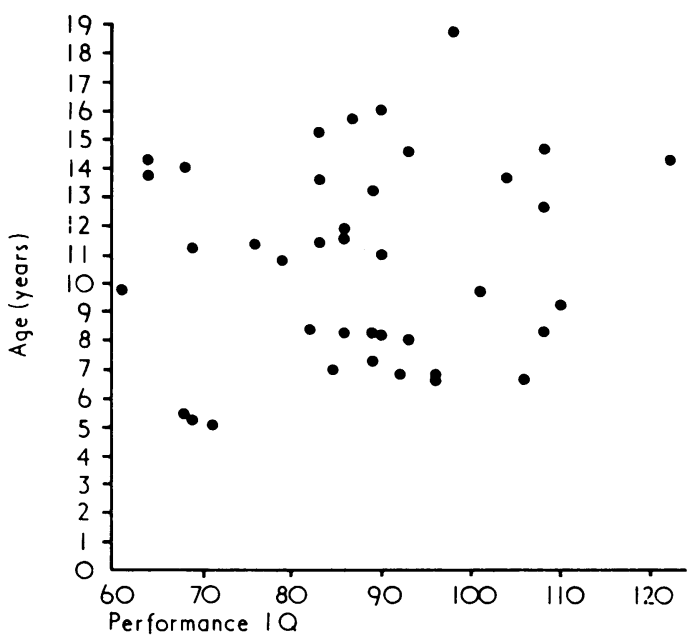

FIG. 4.-Correlation between age and performance $I Q$ in 39 dystrophics.

formance IQ higher than the mean verbal IQ (Sherwin and McCully, 1961; Zellweger and Niedermeyer, 1965; Zellweger and Hanson, 1967), but the present study shows no significant difference. Neither does it show that a significantly greater proportion of patients score higher on the performance subtests than on the verbal subtests; the performance IQ was higher than the verbal in 22 cases, while the verbal was higher in 17 cases.

(2) Subtest scores. 11 subtest scores of DMD patients were compared with those of unaffected subjects in the study, and the means of these scores

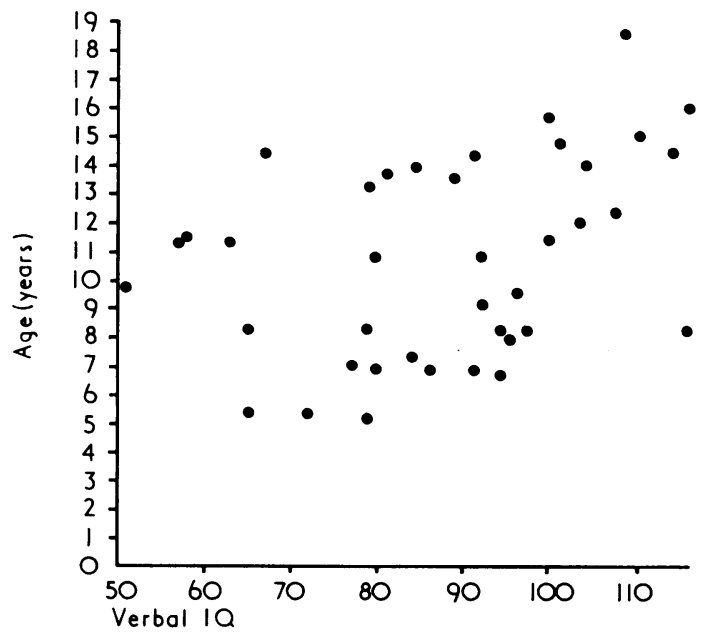

FIG. 5.-Correlation between age and verbal IQ in 39 dystrophics. 
TABLE VII

Mean Subtest Scores of Dystrophics and Unaffected Subjects in the Study

\begin{tabular}{|c|c|c|c|}
\hline & $\begin{array}{c}39 \\
\text { Dystrophics }\end{array}$ & $\begin{array}{l}107 \text { Unaffected } \\
\text { Family } \\
\text { Members }\end{array}$ & Difference \\
\hline $\begin{array}{l}\text { Information } \\
\text { Comprehension } \\
\text { Arithmetic ... } \\
\text { Similarities .. } \\
\text { Vocabulary .. } \\
\text { Digit span .. } \\
\text { Picture completion } \\
\text { Picture arrangemen } \\
\text { Block design } \\
\text { Object assembly } \\
\text { Coding .. }\end{array}$ & $\begin{array}{l}8 \cdot 33 \\
7 \cdot 85 \\
7 \cdot 54 \\
8 \cdot 28 \\
8 \cdot 92 \\
7 \cdot 33 \\
9 \cdot 38 \\
8 \cdot 00 \\
9 \cdot 15 \\
8 \cdot 10 \\
6 \cdot 31\end{array}$ & $\begin{array}{l}10 \cdot 18 \\
10 \cdot 39 \\
10 \cdot 37 \\
10 \cdot 44 \\
10 \cdot 41 \\
10 \cdot 02 \\
10 \cdot 20 \\
10 \cdot 29 \\
11 \cdot 12 \\
10 \cdot 57 \\
10 \cdot 48\end{array}$ & $\begin{array}{l}1 \cdot 85 \\
2 \cdot 54 \\
2 \cdot 83 \\
2 \cdot 16 \\
1 \cdot 49 \\
2 \cdot 69 \\
0 \cdot 82 \\
2 \cdot 29 \\
1 \cdot 97 \\
2 \cdot 47 \\
4 \cdot 17\end{array}$ \\
\hline
\end{tabular}

are shown in Table VII. Though Morrow and Cohen (1954) and Worden and Vignos (1962) reported that DMD patients had specific areas of difficulty, none was found in the present study. Mean scores of 11 subtests were calculated and all were found to be depressed. As the score in the 'coding' subtests depends almost entirely upon speed, it is not unexpected that DMD patients are most deficient in this area.

Secondary effects of severe muscle disability as cause of lower intellectual functioning. Several authors have shown that a reduced IQ in DMD patients is not a secondary or environmental effect of the muscular disability (Allen and Rodgin, 1960; Worden and Vignos, 1962; Zellweger and Niedermeyer, 1965; Zellweger and Hanson, 1967). A 6-point scale, similar but not identical to those used by Worden and Vignos (1962) and Zellweger and Niedermeyer (1965) for classifying the stage of the disease in DMD patients, was used in this study (Table VIII). The correlation coefficient between IQ and stage of the disease was found to be $r=+0.035$ which is not significant. If severe muscle disability led to a lower IQ, a significant negative correlation would be expected. In Fig. 3, 4, and 5 it can be seen that mental subnormality is present early as well as late in the disease process.

TABLE VIII

Functional Classification of Dystrophic Patients

Stage 1-Slightly waddling gait, patient rises from floor with minimal effort, climbs stairs without assistance.

Stage 2-Patient walks slowly and with more conspicuous waddling gait, climbs stairs, and/or gets out of chair with difficulty.

Stage 3-Patient still walks unassisted but cannot climb stairs and/or get out of chair.

Stage 4-Patient walks slowly only with assistance or braces.

Stage 5-Patient is in wheelchair and sits errect.

Stage 6-Patient is in wheelchair and sits errect only with support.
Worden and Vignos (1962) found the mean IQ of 16 patients with what they termed 'amyotonia congenita' (who are handicapped more severely and from an earlier age than DMD patients) to be 118 , which is in the 'bright normal' range, showing that the effects of a severe muscular handicap do not necessarily reduce the intelligence of such children.

Several authors have attempted to correlate the duration of the disease and/or age of onset with IQ (Allen and Rodgin, 1960; Shorer, 1964; Worden and Vignos, 1962). However, the present concept regarding the age of onset is that DMD is present by the time of birth. Serum CK activity is very high in newborns who later develop DMD (Pearson et al., 1961).

Effect of Socio-economic Class on Intelligence. The effect of socio-economic status on the IQ's of DMD patients has been disputed on several occasions. Truitt suggested that the IQ's of DMD patients were within the limits of normal expectation for their socio-economic group. Assuming that the socio-economic status of patients and their sibs was equivalent, and that therefore any difference in IQ between the two could not be attibuted to this, Worden and Vignos (1962) found a significant difference in IQ between DMD patients and their sibs. This finding was repeated in the current study.

Socio-economic class in this study was measured in terms of the annual paternal income. To determine if the lower IQ's among DMD patients was found because the sample derived from a low socio-economic stratum, the data were grouped as in Table IX.

A $2 \times 2$ analysis of variance (Snedecor, 1956) was calculated and the results are shown in Table X. The $F_{1}$ ratio shows that the IQ's of the dystrophics in the upper income bracket are significantly higher than those in the lower bracket, but that this is also true for the sibs. The $F_{2}$ ratio shows that the IQ's of the DMD patients are significantly lower than the IQ's of their unaffected sibs in both income brackets. An

TABLE IX

Mean IQ's of Dystrophics and Unaffected Sibs in Two Income Ranges

\begin{tabular}{|c|c|c|c|c|}
\hline & \multicolumn{2}{|c|}{$\begin{array}{c}\text { Income } \\
<\$ 6500 / \text { year }\end{array}$} & \multicolumn{2}{|c|}{$\begin{array}{c}\text { Income } \\
>\$ 6500 / \text { year }\end{array}$} \\
\hline & $\begin{array}{l}\text { No. of } \\
\text { Subjects }\end{array}$ & Mean IQ & $\begin{array}{l}\text { No. of } \\
\text { Subjects }\end{array}$ & Mean IQ \\
\hline $\begin{array}{l}\text { Duchenne patients } \\
\text { Unaffected sibs .. }\end{array}$ & $\begin{array}{l}23 \\
33\end{array}$ & $\begin{array}{r}82 \cdot 17 \\
104 \cdot 42\end{array}$ & $\begin{array}{l}18 \\
36\end{array}$ & $\begin{array}{r}89 \cdot 39 \\
108 \cdot 72\end{array}$ \\
\hline
\end{tabular}


TABLE X

Analysis of Variance of IQ's of Dystrophics and Unaffected Sibs in Two Income Ranges

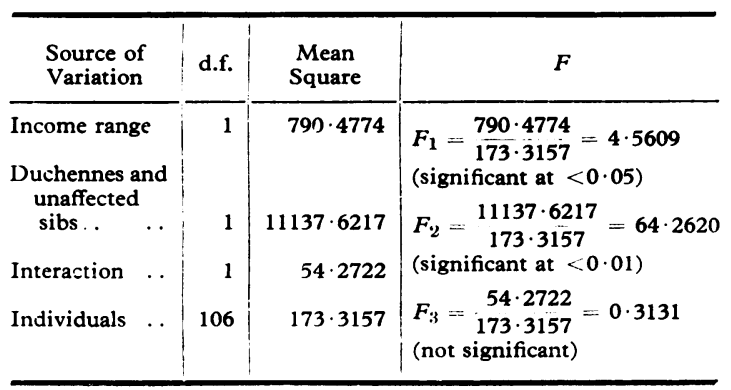

TABLE XI

IQ, Age, and Highest CK Value in 63 Carriers

\begin{tabular}{ll|c|c|c}
\hline & Mean & S.D. & Range \\
\hline IQ & $\ldots$ & $104 \cdot 1$ & $12 \cdot 8$ & $70-139$ \\
Age $(y r / m$ th. $)$ & $\ldots$ & $22 / 3$ & - & $3 / 2-55 / 4$ \\
CK $\ldots$ & $10 \cdot 98$ & - & $1 \cdot 21-116 \cdot 0$ \\
\hline
\end{tabular}

* Defined in Materials and Methods section.

$F_{3}$ ratio which is not significant indicates no interaction between the groups.

Zellweger and Niedermeyer (1965) reported that socio-economic conditions and the IQ's of dystrophic children are correlated. The current study confirms this, but also shows a correlation between socio-economic level and the IQ's of normal sibs. The analysis showed that the mean IQ of DMD patients and their sibs was significantly different in each income group, and by about the same amount in each.

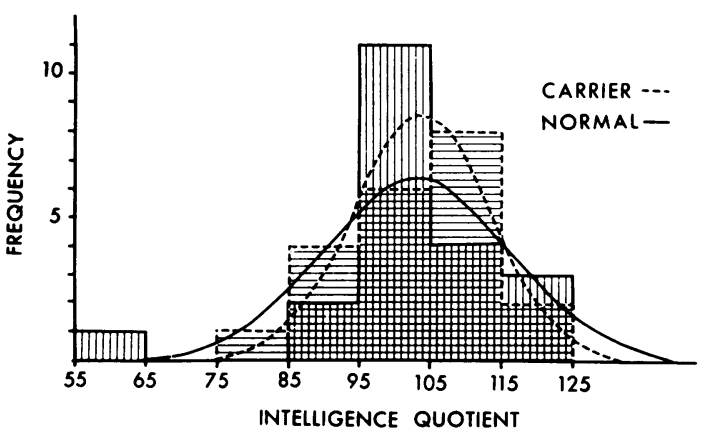

FIG. 6.-Comparison of IQ's (family mean of mothers and children) of carriers and normals in 21 families.

IQ's in heterozygotes.

(1) Intellectual functioning in heterozygous women. The mean, standard deviation, and range of the IQ, age, and highest $C K$ value for 63 carriers are shown in Table XI. In each family the mean IQ of carriers was calculated and paired with the mean IQ of normals in that family (both males and females). An $R \times 2$ analysis of variance was performed on the data obtained in 21 families. The range, distribution, and normal curves of the two groups are shown in Fig. 6. The mean IQ's of the carriers and affected family members, and $F$ ratios obtained by analysis of variance, are shown in Table XII.

The $F_{1}$ ratio indicates that there is no significant difference between the mean IQ of carriers of the Duchenne gene and the mean IQ of unaffected family members. $F_{2}$ indicates that the IQ's of sibships differ, some having higher IQ's than others. $\quad F_{3}$ shows no interaction.

(2) Effect of serum CK activity on IQ of carriers. In order to determine if the level of CK activity

TABLE XII

Mean IQ's and Analysis of Variance of IQ's of Carriers and Normal Family Members

\begin{tabular}{|c|c|c|c|c|c|c|c|c|c|}
\hline & & & & & & & & Mean & S.D. \\
\hline . & & & & $\begin{array}{l}\text { Mean } \\
\text { Mean } \\
\text { mer }\end{array}$ & $\begin{array}{l}\text { of } 37 \\
\text { of } 3 \\
\text { ers }\end{array}$ & $\begin{array}{l}7 \text { carr } \\
34 \text { un }\end{array}$ & $\begin{array}{c}\text { ected family } \\
\ldots\end{array}$ & $\begin{array}{l}103 \cdot 7 \\
103 \cdot 0\end{array}$ & $\begin{array}{r}9 \cdot 7 \\
13 \cdot 1\end{array}$ \\
\hline & Source & of $\mathrm{V}$ & ation & & & d.f. & $\begin{array}{l}\text { Sum of } \\
\text { Squares }\end{array}$ & Mean Square & $F$ \\
\hline Carriers and & normals & . & $\cdots$ & $\cdots$ & $\cdots$ & 1 & & $39 \cdot 1298$ & $F_{1}=\frac{39 \cdot 1298}{126 \cdot 9644}=0.56$ (not significant) \\
\hline Sibships & . & $\cdots$ & $\cdots$ & $\cdots$ & $\cdots$ & 20 & $5190 \cdot 4189$ & $259 \cdot 5209$ & 259.5290 \\
\hline Interaction & $\cdots$ & . & . & . & $\cdots$ & 20 & $2539 \cdot 2885$ & $126 \cdot 9644$ & $F_{2}=\frac{87 \cdot 3928}{8}=2.97$ (significant at $\left.<0.01\right)$ \\
\hline Individuals & $\cdots$ & $\cdots$ & $\cdots$ & . & $\cdots$ & 29 & $2534 \cdot 3916$ & $87 \cdot 3928$ & $F_{3}=\frac{126 \cdot 9644}{87 \cdot 3928}=1 \cdot 45$ (not significant) \\
\hline
\end{tabular}


TABLE XIII

Mean IQ's of Dystrophics and Unaffected Sibs of Carrier and Non-carrier Mothers

\begin{tabular}{l|c|c|c|c}
\hline & \multicolumn{2}{|c|}{ Carrier } & \multicolumn{2}{|c|}{ Non-carrier } \\
\cline { 2 - 5 } \cline { 3 - 5 } & $\begin{array}{c}\text { No. of } \\
\text { Subjects }\end{array}$ & Mean IQ & $\begin{array}{c}\text { No. of } \\
\text { Subjects }\end{array}$ & Mean IQ \\
\hline $\begin{array}{l}\text { Duchenne boys } \\
\begin{array}{l}\text { Unaffected } \\
\text { children }\end{array}\end{array}$ & 37 & 85.97 & 7 & 87.57 \\
\hline
\end{tabular}

in carrier women affected their IQ's a correlation was performed between the highest recorded CK value for each woman and her IQ. The correlation was not significant $(r=-0 \cdot 14)$. Ten carriers had exceptionally high CK values, exceeding 15 units, with a mean value of 45.4 and a range from 14.6 to 116.0 units. The mean IQ of these 10 carriers was $101 \cdot 1$, showing no significant variation from normal.

Intelligence of children of heterozygous females compared with that of children of normal females. If the lowered IQ of DMD patients is a consequence of a biochemical abnormality, such as high serum CK activity, then it might be expected that children born to carrier mothers with raised serum $C K$ activity will show impaired intelligence, as is the case with children born to phenylketonuric mothers (Mabry et al., 1963; Mabry, Denniston, and Coldwell, 1966; Richards, 1964; Fraser, 1968). To determine if there is an effect of the deleterious gene in carrier mothers on the intelligence of their children, the data were grouped and are shown in Table XIII.

A $2+2$ analysis of variance was carried out, and results are shown in Table XIV. $F_{1}$ indicates that there is no significant difference between the IQ's of DMD patients born to carrier mothers and those of patients born to non-carrier mothers; also, that there is no significant difference in the

TABLE XIV

Analysis of Variance of IQ's of Dystrophics and Unaffected Sibs from Carrier and Non-carrier Mothers

\begin{tabular}{|c|c|c|c|}
\hline $\begin{array}{l}\text { Source of } \\
\text { Variation }\end{array}$ & d.f. & $\begin{array}{l}\text { Mean } \\
\text { Square }\end{array}$ & $F$ \\
\hline $\begin{array}{l}\text { Carriers and } \\
\text { non-carriers }\end{array}$ & 1 & $527 \cdot 3030$ & $\begin{array}{l}F_{1}=\frac{527 \cdot 3030}{202 \cdot 6647} \\
\text { (not significant) }\end{array}=2 \cdot 6018$ \\
\hline $\begin{array}{l}\text { Interaction } \ldots \\
\text { Individuals } \ldots\end{array}$ & 123 & $\begin{array}{l}124 \cdot 8890 \\
202 \cdot 6647\end{array}$ & $\begin{array}{l}F_{3}=\frac{124 \cdot 8890}{202 \cdot 6647}=0.6162 \\
\text { (not significant) }\end{array}$ \\
\hline
\end{tabular}

IQ's of normals from the two groups of mothers. $F_{3}$ indicates that there is no interaction.

Dubowitz found that a positive family history was much less frequent in the cases with normal intelligence than in the retarded ones, while Zellweger and Niedermeyer found no difference between familial and sporadic cases. In the present study, though children of non-carrier mothers were observed to have IQ's slightly higher than those of children of carrier mothers, the difference was not significant.

Nature of drop in IQ. In IQ, some classes of retardates (e.g. those with mongolism) more closely resemble other similarly affected children than members of their own families. To determine if the same holds true for DMD patients, a correlation was calculated between the difference in IQ of muscular dystrophy patients from their sib mean, and the sib mean itself. A very significant positive correlation was found $(+0.56$, significant at $<0.01$, Fig. 7), indicating that patients from bright families 'lose' more IQ points than do those from dull families. The percentage change in IQ of dystrophics from the mean IQ of their sibs was calculated, and ranged in individual patients from a $48 \cdot 3 \%$ decrease to a $36 \cdot 8 \%$ increase, with a mean decrease of $18.5 \%$.

The degree of subnormality may depend in part upon the specific family background. The most severely subnormal DMD patients tend to be found in families in which the mean IQ is lower than average, while the patients with normal intelligence appear to derive from more intelligent families. In the Japanese family reported by Suga et al. (1966), the muscular dystrophy patients were severely mentally impaired (with IQ's below

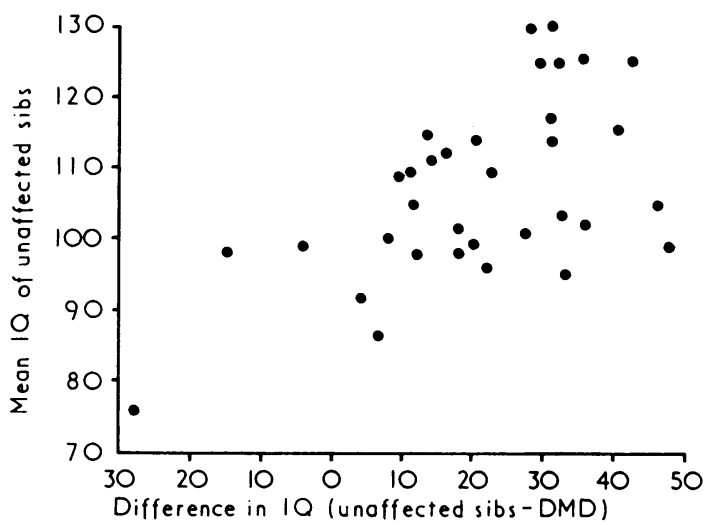

FIG. 7.-Correlation between the mean $I Q$ of unaffected sibs, and the difference in $I Q$ (unaffected sibs-dystrophics). 
60 ), and the mother was also defective. There is a similar family in the current study, in which a borderline defective mother and a father of normal intelligence have three sons with muscular dystrophy, two so severely impaired as to be untestable, and one in the average range. Two other patients who were too severely defective to be scored derive from a family in which the mean IQ of the unaffected sibs is 80 .

\section{Discussion}

DMD patients. In brief summary, the present study has shown that the intelligence of DMD patients is impaired, that the impairment is not progressive in nature, and that it is not correlated with the stage or severity of the disease. Though socio-economic conditions affect the intelligence of patients, they also affect the intelligence of their normal sibs, so cannot be called upon to explain the severe retardation found in many cases of DMD.

The most likely explanation for the mental impairment in DMD is that the Duchenne gene is one with pleiotropic effects, that is, that in addition to the gene's effect on muscle tissue, a biochemical abnormality of either primary or secondary origin affects the development of the brain.

(a) The defect may be a primary consequence of the deleterious gene; that is, the defective gene may directly cause abnormal development of the brain, influencing development of the cerebral hemispheres, including migration of the neurones in the cortex (Rosman and Kakulas, 1966).

(b) The intellectual impairment may be entirely secondary to biochemical abnormalities arising from the dystrophic process in the muscle. Because the mental retardation is not progressive, it is possible that at some particularly vulnerable stage of central nervous system development an insult occurs to the cerebrum, maximum involvement occurring in early life when the brain is most vulnerable. Rosman and Kakulas (1966) think that this is unlikely, since the nature of the cerebral lesions they found during the necropsy for muscular dystrophy patients (including three DMD patients) indicated that the lesions must have been present before serious secondary effects of the dystrophy could have occurred. DMD is present at birth, however, and can be detected at that time by serum enzyme determination (Pearson et al., 1961). The disorder appears to begin before birth, possibly with the initial stages of fetal muscle development. Rosman and Kakulas do not appear to have considered the possibility of the presence of dystrophy in fetal life.
Involvement of multiple tissues in a genetically determined disease is a well-recognized occurrence. For example, in phenylketonuria, in which the primary defect is lack of the liver enzyme phenylalanine hydroxylase, pleiotropic effects include severe mental retardation, lighter pigmentation than normal, and in some instances other neurological features. Though the primary action of the DMD gene remains unknown, it is known that besides causing dystrophy of the skeletal muscle, the gene can lead to changes in the myocardium (e.g., Skyring and McKusick, 1961). Involvement of the central nervous system, as shown in this study, appears to be another effect of the same mutant gene.

DMD heterozygotes. On the assumption that retardation is a pleiotropic effect of the DMD gene, those heterozygotes who show manifestations of myopathy because they have sufficient cells in which the defective $\mathrm{X}$ is active might be expected to show mental subnormality. However, in the present study, heterozygous females were not significantly different from normal controls, and so-called 'manifesting heterozygotes' showed no significant variation from normal.

If mental defect is a primary effect of the defective gene, it may be that since the retardation in patients is relatively mild (only about $1 \mathrm{SD}$ below normal), the effect of the deleterious gene on the brain of heterozygotes is so slight as to be imperceptible. If the mental impairment is a secondary effect of some abnormal biochemical or some biochemical produced in abnormal amounts, it may be that the substance is not present in heterozygotes in sufficient amounts to cause noticeable mental subnormality. The correlation coefficient between IQ and level of CK activity in carriers showed no significant association. However, the $\mathrm{CK}$ activity of carriers rarely approaches the levels found in patients, particularly the levels found in the early stages of the disease when the brain is still immature.

\section{Summary}

Forty-seven DMD patients, their sibs, mothers, and some aunts and cousins were tested with standard intelligence tests: the WISC, WAIS, and Stanford Binet.

The mean intelligence of DMD patients was found to fall approximately 1 SD below the population mean. About $30 \%$ of the patients are mentally defective, that is, have IQ's below 75, as compared to $9 \%$ of the normal population. Unlike the muscle disorder in these patients, the intellectual impairment is not progressive. The 
most likely explanation is that there is an early insult to the developing cerebrum, with no deterioration thereafter. The mental impairment is uniform; both the verbal and performance aspects of the IQ are equally impaired. There is no evidence that mental retardation is a secondary or environmental effect of the severe muscle disability. Mental impairment is found in the early stages of the disease as well as in the later ones. Differences in socio-economic class cannot explain the decrease. At both low and middle income brackets, the IQ's of dystrophics are significantly lower than those of their normal sibs. The degree of mental impairment in sporadic cases (with normal mothers) is not significantly different from that found in familial cases (with heterozygous mothers). The intellectual retardation in Duchenne patients appears to depend on the specific family genetic background; severe retardation is generally found in patients from dull families while normal intelligence is often found in patients from more intelligent families. The intelligence of females heterozygous for the DMD gene is not affected.

\section{REFERENCES}

Allen, J. E., and Rodgin, D. W. (1960). Mental retardation in association with progressive muscular dystrophy. Amer. $\mathcal{f}$. Dis. Child., 100, 208.

Becker, P. E. (1953). Dystrophia Musculorum Progressiva. Thieme, Stuttgart.

Bell, J. (1943). On pseudohypertrophic and allied types of progressive muscular dystrophy. In The Treasury of Human Inheritance, vol. IV, pt. 4. Ed. by R. A. Fisher. Cambridge University Press, London.

Bramwell, E., and Addis, W. R. (1913). Myotonia atrophica. Edinb. med. ., 11, 21.

Dubowitz, V. (1965). Intellectual impairment in muscular dystrophy. Arch. Dis. Childh., 40, 296.

Duchenne, G. B. (1868). Recherches sur la paralysie musculaire pseudo-hypertrophique, ou paralysie myo-sclerosique. Arch. gen. Med., 6th ser., 11, 569.

Emery, A. E. H. (1963). Clinical manifestations in two carriers of Duchenne muscular dystrophy. Lancet, 1, 1126.

- (1964). Lyonisation of the X chromosome. ibid., 1, 884.

- (1965). Muscle histology in carriers of Duchenne muscular dystrophy. F. med. Genet., $2,1$.

- and Lee, C. S. N. (1964). Manifestations in carriers of X-linked muscular dystrophy. Lancet, 2, 1066.

Erb, W. (1891). Dystrophia muscularis progressiva. Klinische und pathologisch-anatomische Studien. Disch. Z. Nervenheilk., 1, 13 and 173.

Fraser, G. R. (1968). Children of phenylketonuric women. Pediatrics, 41, 155.

Gamstorp, I., and Smith, M. (1964). EEG-fynd och testresultat vid myopati och denervationsatrofi $i$ barnaåldern. (EEG findings and test results in myopathy and denervation atrophy in children.) Nord. med., 72, 998.

Giannini, G. del C., and Marcheschi, M. (1959). Sui disturbi psichici nella distrofia muscolare primitiva. Sist. nerv., 11,461 .

Gowers, W. R. (1879). Pseudo-hypertrophic Muscular Paralysis. A Clinical Lecture. Churchill, London.

Jones, H. E. (1965). The environment and mental development. In Manual of Child Psychology, p. 644. Wiley, New York.

Lyon, M. F. (1961). Gene action in the X-chromosome of the mouse (Mus musculus L.). Nature (Lond.), 180, 372.

- (1962). Sex chromatin and gene action in the mammalian X-chromosome. Amer. F. hum. Genet., 15, 135.
Mabry, C. C., Denniston, J. C., and Coldwell, J. G. (1966). Mental retardation in children of phenylketonuric mothers. New Engl. F. Med., 275, 1331.

- - Nelson, T. L., and Son, C. D. (1963). Maternal phenylketonuria. A case of mental retardation in children without the metabolic defect. ibid., 269, 1404.

Morrow, R. S., and Cohen, J. (19j4). The psycho-social factors in muscular dystrophy. $\mathcal{f}$. Child Psychiat. (N.Y.), 3, 70.

Murphy, E. G., and Thompson, M. W. (1969). Manifestations of Duchenne muszular dystrophy in carriers. In Proceedings of the Second International Congress of Neurogenetics and Neuroophthalmology. In the press.

— - - Corey, P. N. J., and Conen, P. E. (1964). Varying manifestations of Duchenne muscular dystrophy in a family with affected females. In Muscle (Proc. of Sympos. at Faculty of Med., University of Alberta). Ed. by W. M. Paul, E. E. Daniel, C. M. Kay, and G. Monckton. Pergamon, New York.

Pearson, C. M., Chowdhury, S. R., Fowler, W. M., Jr., Jones, M. H., and Griffith, W. H. (1961). Studies of enzymes in serum in muscular dystrophy. II. Diagnostic and prognostic significance in relatives of dystrophic persons. Pediatrics, 28, 962.

Richards, B. W. (1964). Maternal phenylketonuria. Lancet, 1, 829.

Rosman, N. P., and Kakulas, B. A. (1966). Mental deficiency associated with muscular dystrophy. Brain, 89, 769.

Scheinfeld, A. (1950). The New You and Heredity. Lippincott, Philadelphia.

Schoelly, M. L., and Fraser, A. W. (1955). Emotional reacticns in muscular dystrophy. Amer. F. phys. Med., 34, 119.

Sherwin, A. C., and McCully, R. S. (1961). Reaction observed in boys of various ages (10-14) to a crippling progressive, and fatal illness (muscular dystrophy). $\mathcal{F}$. chron. Dis., 13, 59.

Shorer, C. E. (1964). Muscular dystrophy and the mind. Psychosom. Med., 26, 5.

Skyring, A., and McKusick, V. A. (1961). Clinical, genetic and electro-cardiographic studies in childhood muscular dystrophy. Amer. F. med. Sci., 242, 534.

Smith, H. L., Amick, L. D., and Johnson, W. W. (1966). Detection of subclinical and carrier states in Duchenne muscular dystrophy. F. Pediat., 69, 67.

Snedecor, G. W. (1956). Statistical Methods, 5th ed. Iowa State University Press, Ames, Iowa.

Suga, M., Yoshimuta, S., Hayashi, Y., and Sakamoto, F. (1966) A family of progressive muscular dystrophy with mental retardation. Clinical observations. $\mathcal{f a p}$. $\mathcal{f}$. hum. Genet., $10,189$.

Thompson, M. W., and Murphy, E. G. (1964). Clinical manifestations of myopathy in female carriers of Duchenne muscular dystrophy (Abstract). Canad. F. Genet. Cytol., 6, 245.

- - and McAlpine, P. J. (1967). An assessment of the creatine kinase test in the detection of carriers of Duchenne muscular dystrophy. f. Pediat., 71, 82.

Truitt, C. J. (1955). Personal and social adjustments of children with muscular dystrophy. Amer. F. phys. Med., 34, 124.

Walton, J. N. (1963). Clinical aspects of human muscular dystrophy. In Muscular Dystrophy in Man and Animals. Ed. by G. H. Bourne and M. N. Golarz. Karger, Basle.

, and Nattrass, F. J. (1954). On the classification, natural history and treatment of the myopathies. Brain, 77, 169.

Wechsler, D. (1949). Wechsler Intelligence Scale for Children. The Psychological Corporation, New York.

Worden, D. K., and Vignos, P. J., Jr. (1962). Intellectual function in childhood progressive muscular dystrophy. Fediatrics, 29, 968.

Zellweger, H. (1946). UUber Knochenveränderungen bei der Dystrophia musculorum progressiva. Ann paediat. (Basel), 167, 287.

dystrophy type IIIa (Duchenne). Develop. Med. Child Neurnl., $9,576$.

- and Niedermeyer, E. (1965). Central nervous system manifestations in childhood muscular dystrophy. I. Psychometric and electroencephalographic findings. Ann paediat. (Basel), 205, 25.

Correspondence to Margaret W. Thompson, Department of Genetics, Hospital for Sick Children, 555 University Avenue, Toronto 2, Ontario, Canada. 